\title{
PELAKSANAAN DAK FISIK BIDANG PENDIDIKAN DI KABUPATEN AGAM
}

\author{
Oleh: Lisna Sulinar Sari*
}

\begin{abstract}
ABSTRAK
Tujuan penelitian ini adalah untuk mengetahui pelaksanan DAK Fisik jenjang Pendidikan Dasar (Dikdas) di Kabupaten Agam. Penelitian ini menggunakan pendekatan kualitatif. Responden adalah Kepala Bidang SD dan SMP, serta pengelola DAK Fisik Bidang SD dan SMP. Teknik pengumpulan data dilakukan dengan menggunakan diskusi kelompok terpumpun (DKT) dan menggunakan data sekunder. Analisis data menggunakan deskriptif kualitatif. Hasil penelitian menunjukan, bahwa pelaksanaan peningkatan prasarana pendidikan dilakukan secara swakelola dan pengadaan peningkatan sarana pendidikan dilakukan secara lelang atau melalui e-katalog. Pelaksanaan peningkatan prasarana pendidikan dapat dilakukan semuanya (100\%) baik itu di SD maupun di SMP. Sedangkan untuk pengadaan peningkatan sarana pendidikan tidak semuanya dapat dilaksanakan, khususnya di SD. Untuk pengadaan koleksi perpustakaan Bidang SD harus mengembalikan dana sebanyak Rp2,6 Miliar, karena tidak dapat melaksanakan pengadaan koleksi perpustakaan yang disebabkan tidak adanya penyedia yang lulus seleksi sebagai pemenang lelang. Untuk pengadaan peralatan dan media pendidikan di SMP dapat dilaksanakan, karena semua barang yang dibutuhkan dalam pengadaan peralatan dan media pendidikan ada di dalam e-katalog sehingga mempermudah pengelola DAK dalam pengadaan peningkatan sarana pendidikan. Selain itu, proses pengadaan melalui e-katalog lebih cepat dan aman.

Kata Kunci: DAK Fisik Bidang Pendidikan, Pendidikan Dasar, Peningkatan Prasarana.
\end{abstract}

\begin{abstract}
The aim of this study was to find out the implementation of the Physical Special Allocation Fund (DAK) in the Basic Education level in Agam Regency. This study uses a qualitative approach. Respondents were Head of Elementary and junior SecondarySchool Division, as well as managers of Physical DAK in Elementary and Middle School. Data collection were carried out using clustered group discussions (DKT) and secondary data. Analysis data used qualitative descriptive technique. The results of the study show that the implementation of education infrastructure improvement is carried out in a self-managed manner and the procurement of educational facilities is carried out by auction or by e-catalog. All of the education infrastructure improvements can be carried out (100\%) both in elementary and junior high schools. Whereas not all can be implemented to improve education facilities, especially in elementary schools. To procure library collections in the Elementary School, Elementary School Division in the regency must refund as much as IDR 2.6 billion, because it cannot carry out the procurement of library collections due to the absence of providers who pass the selection for auction. Procurement of educational equipment and media can be implemented in Junior Secondary School, because all goods needed in the procurement of equipment and educational media are in the e-catalog, making it easier for DAK managers to procure an increase in educational facilities. In addition, the ecatalog procurement process is faster and safer.
\end{abstract}

Keywords: Physical DAK for Education, Elementary Education, Improving Infrastructure.

\footnotetext{
* Peneliti Pusat Penelitian Kebijakan Pendidikan dan Kebudayaan (Puslitjakdikbud), Badan Penelitian dan Pengembangan Kementerian Pendidikan dan Kebudayaan. Email: lisnapuslit@gmail.com
} 


\section{A. Pendahuluan}

Kabupaten Agam merupakan salah satu Kabupaten yang terdapat di Propinsi Sumatera Barat, yang Ibukotanya adalah Lubuk Basung. Jumlah Penduduk Kabupaten Agam pada tahun sebanyak 484.288 jiwa yang terdiri dari 238.326 penduduk laki-laki dan 245.962 penduduk perempuan. Jumlah penduduk Kabupaten Agam usia 5 - 19 tahun adalah 139.669 jiwa. Angka Partisipasi Kasar (APK) Pendidikan Dasar (Dikdas) di Kabupaten Kasar, yaitu SD memiliki APK 100,28 dan SMP APKnya 95,08. Sedangkan APM Dikdas di Kabupaten Agam adalah SD memiliki APM 87,38 dan SMP APMnya 71,15. Angka putus sekolah di SD cukup rendah, yaitu 0,11 dan angka putus sekolah di SMP lebih besar dari SD, yakni 0,35. Jumlah sekolah dan kelas berdasarkan kondisi dapat dilihat pada Tabel 1.1 berikut ini. (Badan Pusat Statistik, 2018)

Tabel 1.1.

Jumlah Sekolah SD, SMP, dan Ruang Kelas yang dimiliki Berdasarkan Kondisi di Kabupaten Agam pada Tahun 2017.

\begin{tabular}{|l|r|r|}
\hline \multicolumn{1}{|c|}{ Komponen } & \multicolumn{1}{c|}{ SD } & \multicolumn{1}{c|}{ SMP } \\
\hline Jml Sekolah & 448 & 62 \\
\hline Kelas Baik & 853 & 220 \\
\hline Kelas rusak ringan & 2.000 & 382 \\
\hline Kelas rusak berat & 166 & 119 \\
\hline $\begin{array}{l}\text { Jumlah Kelas } \\
\text { seluruhnya }\end{array}$ & 3.019 & 721 \\
\hline
\end{tabular}

Sumber: Disdik Kab.Agam (Badan Pusat Statistik, 2018)
Pada Tabel 1.1, menunjukan bahwa Kabupaten Agam memiliki jumlah SD lebih banyak $(98,62 \%)$ dari jumlah SMP. Begitu pula dengan jumlah kelas di SD lebih banyak $(76,12 \%)$ dari jumlah kelas di SMP. Dan kondisi ruang kelas yang terbanyak juga terdapat di SD dengan kondisi ruang kelas rusak ringan. Pada dasarnya masih banyak SD dan SMP di Kabupaten Agam yang membutuhkan bantuan untuk memperbaiki ruang kelas rusak baik itu rusak ringan maupun rusak berat.

Selain itu, dalam Peraturan Pemerintah Nomor 19 tahun 2005 Tentang Standar Nasional Pendidikan (SNP), Pasal 42, Ayat (1) dan (2), mengatakan bahwa,

"Setiap satuan pendidikan wajib memiliki sarana yang meliputi perabot, peralatan pendidikan, media pendidikan, buku dan sumber belajar lainnya, bahan habis pakai, serta perlengkapan lain yang diperlukan untuk menunjang proses pembelajaran yang teratur dan berkelanjutan. Setiap satuan pendidikan wajib memiliki prasarana yang meliputi lahan, ruang kelas, ruang pimpinan satuan pendidikan, ruang pendidik, ruang tata usaha, ruang perpustakaan, ruang laboratorium, ruang bengkel kerja, ruang unit produksi, ruang kantin, instalasi daya dan jasa, tempat berolahraga, tempat beribadah, tempat bermain, tempat berkreasi, dan ruang/tempat lain yang diperlukan untuk menunjang proses pembelajaran yang teratur dan berkelanjutan". 
Pada Pasal 47, Ayat (1), (2), dan (3) menyatakan bahwa,

"Pemeliharaan sarana dan prasarana pendidikan sebagaimana dimaksud dalam Pasal 42 sampai dengan Pasal 46 menjadi tanggung jawab satuan pendidikan yang bersangkutan. Pemeliharaan sebagaimana dimaksud pada ayat (1) dilakukan secara berkala dan berkesinambungan dengan memperhatikan masa pakai. Pengaturan tentang masa pakai sebagaimana dimaksud pada ayat (2) ditetapkan dengan Peraturan Menteri”.

Untuk memenuhi sarana dan prasarana yang terdapat dalam standar sarana dan prasarana seperti yang diuraikan di atas, belum semua sekolah di Kabupaten Agam dapat memenuhinya, apalagi sekolah yang berada di daerah terpencil. Jika hanya mengandalkan bantuan operasional sekolah (BOS), sekolah tidak akan dapat memenuhi standar sarana dan prasarana, karena jumlah dana BOS yang diberikan disesuaikan dengan jumlah siswa yang terdapat dalam satu sekolah. Sekolah yang memiliki jumlah siswa banyak, maka akan memperoleh dana BOS besar dan bagi sekolah yang memiliki jumlah siswa sedikit, maka dana BOS yang diperoleh juga sedikit. Padahal biaya operasional untuk proses pembelajaran untuk jumlah siswa banyak dan sedikit sama. Dan pemanfaatan dana BOS seperti yang terdapat dalam Peraturan Menteri Pendidikan Republik Indonesia Nomor 26 Tahun 2017,
Tentang Perubahan atas Peraturan Menteri Pendidikan dan Kebudayaan Nomor 8 Tahun 2017 Tentang Petunjuk Teknis Bantuan Operasional Sekolah (BOS), Lampiran Bab V, Penggunanaan Dana Sub B. Komponen Pembiayaan BOS pada SD/SDLB dan SMP/SMPLB, ketentuan penggunaan BOS pada SD dan SMP, yaitu: (i) pengembangan perpustakaan; (ii) penerimaan peserta didik baru; (iii) kegiatan pembelajaran dan ekstrakurikuler; (iv) kegiatan evaluasi pembelajaran; (v) pengelolaan sekolah; (vi) pengembangan profesi guru dan tenaga kependidikan, serta pengembangan manajemen sekolah; (vii) langganan daya dan jasa; (viii) pemeliharaan dan perawatan sarana dan prasarana sekolah; (ix) pembayaran honor; (x) pembelian/perawatan alat multimedia pembelajaran; dan (xi) biaya lainnya. Untuk SD dam SMP, dana BOS yang bisa digunakan untuk memenuhi Pasal 42, Ayat (1) dan (2) PP SNP adalah point (i), (vi), dan (ix). Sedangkan untuk memenuhi Pasal 47, Ayat (1) dan (2), yaitu point (vii). Namun, pada kenyataannya masih banyak sekolah yang belum bisa mencukupi kebutuhan sarana dan prasarana pendidikan sesuai rasio siswa.

Oleh sebab itu, pemerintah berupaya memberikan bantuan kepada sekolah untuk membantu memenuhi pengadaan sarana dan 
prasarana pendidikan di sekolah-sekolah yang sangat membutuhkan berupa Dana Alokasi Khusus (DAK) Fisik Bidang pendidikan. DAK Fisik merupakan dana perimbangan dari pusat yang ditranfers ke daerah untuk membantu urusan wajib daerah dalam mendanai kegiatan pendidikan dasar dan menengah terkait layanan publik dalam mencapai standar pelayanan minimal (SPM) dan SNP sesuai dengan prioritas nasional.

Berdasarkan Peraturan Presiden Nomor 123 Tahun 2016, Tentang Petunjuk Teknis Dana Alokasi Khusus, Pasal 2, Ayat (1), (2), dan (3), menjelaskan bahwa, "DAK Fisik ada tiga jenis, yaitu DAK Fisik Regular, DAK Fisik Penugasan, dan DAK Fisik Afirmasi. DAK Fisik Reguler meliputi bidang: pendidikan, kesehatan, perumahan dan pemukiman, pertanian, kelautan dan perikanan, sentra industri kecil dan menengah, serta pariwisata. DAK Fisik Penugasan mencakup bidang: pendidikan sekolah menengah kejuruan, kesehatan rumah sakit rujukan/pratama, air minum, sanitasi, jalan, pasar, irigasi, dan energy skala kecil. Sedangkan DAK Fisik Afirmasi meliputi bidang: perumahan dan pemikiman, transportasi, dan kesehatan”. (Republik Indonesia, 2016) Bantuan untuk pendidikan terdapat dalam DAK Fisik regular dan Penugasan pada tahun 2017. Tujuan pemberian bantuan DAK Fisik Reguler adalah untuk membantu mendanai kegiatan penyedian pelayanan dasar dengan target pemenuhan SPM dengan ketersediaan sarana dan prasarana. Sedangkan DAK Fisik Penugasan khusus pendidikan diberikan untuk mendukung pencapaian prioritas pendidikan nasional, yaitu meningkatkan pendidikan SMK yang bermutu dan lulusannya dapat bersaing dalam dunia kerja internasional.

Sasaran DAK Fisik tahun 2017 ditujukan kepada satuan pendidikan SD, SMP, SMA, dan SMK. DAK Fisik Bidang Pendidikan bertujuan untuk membantu: (i) menyediakan ruang belajar/ruang penunjang lainnya yang nyaman dan aman untuk proses pembelajaran; (ii) memenuhi kebutuhan jumlah ruang kelas sesuai standar sarana dan prasarana pendidikan; (iii) menyediakan prasarana penunjang mutu pembelajaran berupa laboratorium IPA untuk SMP dan SMA; (iv) menyediakan sarana penunjang mutu pembelajaran berupa koleksi perpustakaan untuk SD, penyediaan alat pendidikan dan/atau media pendidikan untuk SMP dan SMA; dan (v) menyediakan sarana dan prasarana kegiatan praktik kompetensi kerja dan praktik realiasasi produk teaching factory untuk SMK. 
Pengelolaan DAK Fisik Bidang Pendidikan jenjang pendidikan dasar (Dikdas) dikelola oleh Disdik Kabupaten/Kota di Bidang SD dan SMP. Sedangkan DAK Fisik jenjang pendidikan menengah (Dikmen) dikelola oleh Disdik Propinsi Bidang SMA dan SMK. Oleh sebab itu, peneliti ingin melakukan kajian Pelaksanaan DAK Fisik Bidang Pendidikan di Kabupaten Agam.

Rumusan permasalahan yang dapat disimpulkan dari uraian di atas, yaitu:

1. Bagaimana pelaksanaan DAK Fisik Bidang Pendidikan di Kabupaten Agam?

2. Kendala apa saja yang dihadapi dalam Pelaksanaan DAK Fisik Bidang Pendidikan di Disdik Kabupaten Agam? Sedangkan tujuan dari kajian ini, yaitu:

1. Mengetahui pelaksanaan DAK Fisik Bidang Pendidikan di Kabupaten Agam.

2. Mengetahui kendala yang dihadapi dalam pelaksanaan DAK Fisik Bidang Pendidikan di Disdik Kabupaten Agam.

Lingkup kajian ini adalah Pengelola DAK Fisik Bidang Pendidikan di Kabupaten Agam Bidang SD dan SMP. Manfaat dari hasil penelitian ini untuk memberikan saran kebijakan bagi pengelola DAK Fisik Bidang Pendidikan di Kabupaten Agam agar lebih baik lagi.

\section{B. Kajian Pustaka}

\section{Pengertian Pelaksanaan}

Menurut Kamus Besar Indonesia pelaksanaan, yaitu proses, cara, perbuatan melaksanakan (rancangan, keputusan, dan sebagainya). Pelaksanaan menurut Sastropoetro (1982), yaitu suatu usaha atau kegiatan tertentu yang dilakukan untuk mewujudkan rencana atau program dalam kenyataannya. Wiestra, dkk (dalam Adisasmita, Rahardjo, 2011) mengemukakan bahwa, pelaksanaan merupakan usaha-usaha yang dilakukan untuk melaksanakan semua rencana dan kebijaksanaan yang telah dirumuskan dan ditetapkan dengan melengkapi segala kebutuhan alat-alat yang diperlukan, siapa yang akan melaksanakan, dimana tempat pelaksanaannyaa, dan kapan waktu dimulainya. Berdasarkan uraian tersebut, dapat diambil kesimpulan bahwa, pelaksanaan adalah suatu proses, cara, perbuatan, usaha atau kegiatan tertentu yang dilakukan untuk mewujudkan rencana atau program atau kebijaksanaan yang telah dirumuskan dan ditetapkan dengan melengkapi segala kebutuhan alatalat yang diperlukan, siapa yang akan melaksanakan, dimana tempat pelaksanaannya, dan kapan waktu dimulainya. 
Menurut Abdullah, Syukur (1987), faktor-faktor yang mempengaruhi berhasilnya suatu pelaksanaan adalah:

a. Komunikasi, merupakan suatu program yang dapat dilaksanakan dengan baik apabila jelas bagi para pelaksana. Hal ini menyangkut proses penyampaian informasi, kejelasan informasi dan konsistensi informasi yang disampaikan.

b. Resources (sumber daya), dalam hal ini meliputi empat komponen, yaitu terpenuhinya jumlah staf dan kualitas mutu, informasi yang diperlukan guna pengambilan keputusan atau kewenangan yang cukup guna melaksanakan tugas sebagai tanggung jawab dan fasilitas yang dibutuhkan dalam pelaksanaan.

c. Disposisi, sikap dan komitmen dari pada pelaksanaan terhadap program khususnya dari mereka yang menjadi implementasi program khususnya dari mereka yang menjadi implementer program

d. Struktur birokrasi, yaitu SOP (Standar Operating Procedures) yang mengatur tata aliran dalam pelaksanaan program. Jika hal ini tidak sulit dalam mencapai hasil yang memuaskan, karena penyelesaian masalah- masalah akan memerlukan penangan dan penyelesaian khusus tanpa pola yang baku.

Selain itu, dalam proses implementasi ada tiga unsur yang penting dan mutlak, yaitu:

a. Adanya program kebijakan yang dilaksanakan; b. Kelompok masyarakat yang menjadi sasaran dan manfaat dari program perubahan dan peningkatan; c. Unsur pelaksana baik organisasi maupun perorangan yang bertanggungjawab dalam pengelolaan pelaksanaan dan pengawasan dari proses implementasi tersebut.

\section{DAK}

Berdasarkan Peraturan Menteri

Pendidikan dan Kebudayaan Nomor 25

Tahun 2017 Tentang Perubahan Atas

Peraturan Menteri Pendidikan dan

Kebudayaan Nomor 25 Tahun 2017

Tentang Petunjuk Operasional Dana

Alokasi Khusus Fisik Bidang Pendidkan,

Pasal 1, Ayat (1), menyatakan bahwa, "DAK Fisik Bidang Pendidikan, yaitu dana yang bersumber dari pendapatan APBN yang dialokasikan kepada Daerah tertentu dengan tujuan mendanai kebutuhan sarana dan/atau prasarana bidang pendidikan yang merupakan urusan daerah". Jadi pengelolaan DAK Fisik Bidang Pendidikan, yaitu suatu tindakan yang dimulai dari proses penyusunan data, merencanakan, melaksanakan, melakukan pengawasan, dan penilaian pada semua hal yang terlibat dalam pelaksanaan DAK Fisik Bidang Pendidikan dalam pencapaian tujuan DAK Fisik Bidang Pendidikan.

Pemerintah Kabupaten/Kota bertugas dan bertanggungjawab: a. mengusulkan rincian dan lokasi serta target output kegiatan DAK Fisik Bidang Pendidikan 
SD dan SMP berdasarkan rencana kegiatan DAK fisik yang disusun Dinas Pendidikan; b. menyalurkan dana ke sekolah penerima DAK Fisik Bidang Pendidikan SD dan SMP untuk kegiatan peningkatan prasarana pendidikan, kecuali pemerintah kabupaten/kota di Provinsi Papua dan Provinsi Papua Barat; dan c. bertanggung jawab terhadap pelaksanaan program DAK Fisik Bidang Pendidikan SD dan SMP di tingkat kabupaten/kota.

Sedangkan Disdik Kabupaten/Kota bertugas dan bertanggungjawab: a. melakukan perencanaan alokasi dan jumlah sekolah penerima DAK Fisik Bidang Pendidikan SD dan SMP tahun anggaran berkenaan; b. membentuk tim teknis, yang bertugas: 1). menentukan tingkat kerusakan ruang/ bangunan dengan melibatkan unsur teknis yang ada di daerah tersebut; dan 2). menyusun rencana kegiatan sekolah bersama P2S. c. menandatangani surat perjanjian pemberian bantuan kegiatan peningkatan prasarana pendidikan DAK Bidang Pendidikan SD dan SMP tahun anggaran berkenaan dengan kepala sekolah penerima DAK, kecuali untuk kabupaten/kota di Provinsi Papua dan Papua Barat; d. menyelenggarakan bimbingan teknis pelaksanaan peningkatan prasarana pendidikan kepada kepala sekolah dan komite sekolah, agar memahami secara teknis mekanisme dan tata kelola pelaksanaan kegiatan peningkatan prasarana pendidikan, kecuali Dinas Pendidikan Kabupaten/Kota yang berada di Provinsi Papua dan Provinsi Papua Barat; e. melaksanakan pengadaan sarana pendidikan sesuai dengan ketentuan peraturan perundangundangan; f. melaksanakan monitoring dan evaluasi; g. melaksanakan penilaian kinerja terhadap pelaksanaan DAK Fisik Bidang Pendidikan SD dan SMP di kabupaten/kota; dan h. melaporkan pelaksanaan DAK Bidang Pendidikan SD dan SMP tahun anggaran berkenaan kepada Menteri Pendidikan dan Kebudayaan melalui Direktur Jenderal Pendidikan Dasar dan Menengah.

Dewan Pendidikan provinsi/kabupaten/ kota bertugas dan bertangungjawab: a. memberikan pertimbangan dan dukungan dalam pelaksanaan DAK Fisik Bidang Pendidikan di tingkat provinsi/kabupaten/ kota; dan b. melakukan pengawasan dalam rangka transparansi dan akuntabilitas pelaksanaan DAK Fisik 
Bidang Pendidikan di tingkat provinsi/ kabupaten/kota.

Ketentuan Umum Pelaporan, yaitu: a. Pelaporan dilakukan secara berjenjang, mulai dari laporan panitia tingkat sekolah, kepala sekolah, provinsi/kabupaten/kota, dan pusat, memuat: 1). kemajuan pelaksanaan kegiatan sesuai indikator kinerja; dan 2). realisasi fisik dan keuangan serta masalah dan kendala pelaksanaan anggaran. b. Kualitas pelaporan: 1). untuk mewujudkan transparasi dan akuntabilitas laporan disampaikan tepat waktu dan akurat serta disusun dengan mengikuti petunjuk yang berlaku; 2). laporan harus baik, benar, jujur dan dapat dipertanggungjawabkan; 3). ketaatan dan ketepatan waktu pengiriman laporan merupakan indikator keseriusan dalam melaksanakan pembangunan pendidikan; dan 4). kualitas laporan akan dijadikan salah satu indikator reward dan punishment bagi setiap Kabupaten/Kota. c. Kepatuhan provinsi/ kabupaten/kota dalam penyampaian laporan akan dijadikan sebagai salah satu indeks teknis penetapan alokasi DAK tahun berikutnya.

DAK Fisik Reguler Bidang Pendidikan SD untuk peningkatan prasarana pendidikan meliputi: rehabilitasi ruang belajar, ruang guru, dan/atau jamban dengan tingkat kerusakan sedang atau berat, baik berikut perabotnya atau tanpa perabotnya; dan/atau pembangunan ruang kelas baru (RKB) berikut perabotnya. Sedangkan peningkatan sarana pendidikan berupa pengadaan koleksi perpustakaan (buku pengayaan, buku referensi, dan buku panduan pendidik).

\section{DAK Fisik Bidang Pendidikan} peningkatan prasarana pendidikan untuk SMP mencakup: rehabilitasi ruang belajar dan/atau ruang penunjang lainnya dengan tingkat kerusakan minimal sedang, baik beserta perabot atau tanpa perabotnya; pembangunan RKB beserta perabotnya; dan/atau pembangunan laboratorium Ilmu Pengetahuan Alam (IPA) beserta perabotnya. Sedangkan untuk peningkatan sarana pendidikan berupa pengadaan peralatan pendidikan dan/atau media pendidikan. Untuk peralatan pendidikan terdiri dari pengadaan peralatan: Matematika, Laboratorium IPA (Kimia dan Biologi), Laboratorium komputer, IPS, PJOK, dan Seni Budaya. Sedangkan media pendidikan terdiri dari pengadaan proyektor dan komputer pembelajaran di kelas. 
Laporan pertanggungjawaban bersifat berjenjang mulai dari Panitia Pembangunan Sekolah (P2S) ke Kepala Sekolah, Kepala Sekolah ke Pengelola DAK di Disdik Provinsi/Kabupaten/Kota dan seterusnya. Laporan yang harus dibuat oleh P2S mencakup laporan mingguan, bulanan, dan akhir disertai dengan bukti fisik, administrasi, dan keuangan yang dilaporkan kepada Kepala Sekolah. Sedangkan laporan Kepala Sekolah ke Pengelola DAK di Disdik Kabupaten/ Kota terdiri dari: a. laporan pertanggung jawaban mingguan yang meliputi: 1). informasi volume, satuan, dan bobot pekerjaan; 2). prestasi pekerjaan mingguan; 3). jumlah dana yang digunakan; dan 4). foto-foto kemajuan pelaksanaan kegiatan mencakup tampak depan, tampak belakang, tampak samping dan tampak dalam yang diambil dari titik tetap/titik yang sama; b. laporan bulanan yang meliputi: 1). informasi volume, satuan, dan bobot pekerjaan; 2). prestasi pekerjaan bulanan; 3). jumlah dana yang digunakan; dan 4). foto-foto kemajuan pelaksanaan kegiatan mencakup tampak depan, tampak belakang, tampak samping dan tampak dalam yang diambil dari titik tetap/titik yang sama; c. laporan akhir meliputi: 1). dokumen penyelesaian fisik; 2). dokumen penggunaan dana; dan 3). foto-foto pelaksanaan kegiatan $(0 \%, 40 \%$, $70 \%$, dan $100 \%$ ) yang diambil dari titik tetap/titik yang sama.

Sejak tahun 2017 Pemerintah Daerah tidak diharuskan untuk mengalokasikan dana pendamping sebesar $10 \%$ dari dana APBD. Bahkan sejak tahun 2017 Pengelola DAK Fisik diperbolehkan mengambil 5\% bantuan DAK Fisik untuk pelaksanaan manajemen, yang memanfaatannya untuk: a. desain perencanaan; b. biaya tender; c. honorarium fasilitator kegiatan DAK Fisik yang dilakukan secara swakelola; d. penunjukan konsultan pengawas kegiatan kontraktual; e. penyelenggaraan rapat koordinasi; dan f. perjalanan dinas ke/dari lokasi kegiatan dalam rangka perencanaan, pengendalian, dan pengawasan.

\section{Metode Penelitian}

Pendekatan yang digunakan dalam penelitian ini adalah pendekatan kualitatif. Pendekatan kualitatif digunakan untuk menggali data dan informasi terkait pengelolaan DAK Fisik di Disdik Kabupaten Agam. Teknik pengumpulan data dan 
informasi dilaksanakan dengan Diskusi Kelompok Terpumpun (DKT). Data yang digunakan adalah data DAK Fisik Bidang Pendidikan tahun 2017 pada Bidang SD dan SMP. Nara sumber adalah pengelola DAK Fisik Bidang Pendidikan Disdik Kabupaten Agam Bidang SD dan SMP. DKT dan wawancara dilakukan bertujuan untuk mendapatkan informasi lebih dalam pelaksanaan DAK Fisik Bidang Pendidikan dan kendala yang dihadapi oleh pengelola DAK Fisik Bidang Pendidikan di Disdik Kabupaten Agam Bidang SD dan SMP.

Teknik pengumpulan data dan informasi menggunakan panduan DKT yang diperuntukkan bagi pengelola DAK Fisik Bidang SD dan SMP untuk menggali data dan informasi tentang pelaksanaan dan kendala yang dihadapi dari pengelola DAK Fisik Bidang Pendidikan di Disdik Kabupaten Agam Bidang SD dan SMP. Pengolahan dan analisis data menggunakan analisis deskriptif kualitatif.

\section{Hasil dan Pembahasan}

APBD Kabupaten Agam tidak mengalokasikan dana pendamping DAK sejak dihapuskan oleh Pusat. APBD Kabupaten Agam difokuskan untuk membantu pemeliharaan prasarana. Pada
Bidang SD ada program pengecatan sekolah yang dilaksanakan minimal dua tahun sekali. Selain itu ada program prioritas bersih-bersih sekolah yang bekerjasama dengan Bidang SMP, yaitu perbaikkan WC sekolah. Sehingga untuk rehabilitasi dan pembangunan RKB dan pengadaan sarana pendidikan difokuskan dari APBN.

Pengelolaan DAK Fisik Bidang Pendidikan di Kabupaten Agam terpisah antara SD dan SMP dan pengelolanya adalah Kasi Sarana dan Prasarana pada masingmasing bidang. Pengelolaan DAK Fisik Bidang Pendidikan yang akan dibahas terdiri dari aspek perencanaan, aspek pelaksanaan, aspek pengawasan/monev, dan aspek pelaporan.

1. Pelaksanaan DAK Fisik Bidang Pendidikan di Disdik Kabupaten Agam.

a. Perencanaan

Salah satu tugas dari Disdik Kabupaten dalam pelaksanaan DAK Fisik Bidang Pendidikan, yaitu melakukan perencanaan alokasi dan jumlah sekolah penerima DAK Fisik Bidang Pendidikan SD dan SMP tahun anggaran berkenaan. Dalam melaksanakan tugas tersebut, pengelola DAK Fisik Bidang SD dan SMP mengusulkan data sekolah yang masuk 
dari hasil musyawarah rencana pembangunan (musrenbang) dari tingkat nagari (desa) dan kecamatan. Data yang masuk kemudian diverifikasi dengan melihat Dapodik dan mendatangi langsung ke sekolah bersama dengan fasilitator untuk menilai tingkat kerusakan ruang belajar yang akan direhab dan melihat lahan yang akan dibangun. Selain itu, Disdik Bidang SD dan SMP juga meminta data langsung ke sekolah, kemudian membandingkan berapa data sekolah yang dari musrenbang, kalau masih kurang ditambah dari data Disdik yang meminta langsung ke sekolah. Kemudian data tersebut direkap oleh Disdik dan Bappeda dan menjadi usulan data sekolah yang akan diajukan ke pusat untuk mendapatkan bantuan DAK Fisik Bidang Pendidikan yang dimasukan dalam usulan rencana kegiatan (URK).

Tugas selanjutnya dari Disdik Kabupaten, yaitu membentuk tim teknis terdiri dari fasilitator/konsultan yang bertugas: menentukan tingkat kerusakan ruang/bangunan dengan melibatkan unsur teknis di daerah tersebut dan menyusun rencana kegiatan sekolah bersama P2S.

Rehabilitasi ruang belajar rusak sedang jika kerusakan sebagian komponen non struktural, dan atau komponen struktural seperti struktur atap, lantai, dan sejenisnya, dengan tingkat kerusakan lebih dari 30\%-45\%. Rusak berat jika kerusakan pada sebagian besar komponen bangunan, baik struktural maupun nonstruktural yang apabila setelah diperbaiki masih dapat berfungsi dengan baik sebagaimana mestinya, dengan tingkat kerusakan lebih besar dari 45\%-65\%, jika kerusakan lebih dari $65 \%$ maka dapat dilakukan pembangunan kembali.

Sedangkan untuk pembangunan RKB diberikan kepada sekolah yang mempunyai potensi berkembang (dalam tiga tahun terakhir jumlah siswa stabil atau meningkat), memiliki jumlah rombongan belajar melebihi jumlah ruang kelas yang ada, dan memiliki lahan yang luasnya minimal $72 \mathrm{~m} 2(8 \mathrm{~m} \times 9 \mathrm{~m})$ dengan ketentuan pemakaian lahan tersebut tidak mengurangi lapangan upacara atau lapangan olah raga. Jika tidak memiliki 
lahan, maka pembangunan RKB dibangun di lantai 2.

Untuk membantu sekolah dalam pelaksanaan pembangunan DAK Fisik Disdik Kabupaten Agam menyediakan fasilitator/konsultan untuk SD dan SMP penerima peningkatan prasarana pendidikan, seperti rehabilitasi ruang belajar, pembangunan RKB, dan laboratorium IPA. Fasilitator ini tidak hanya membantu dalam perencanaan saja, tetapi hingga pembangunan atau rehab selesai. Fasilitator membantu membuatkan denah ruang yang akan direhab atau dibangun, membantu membuat RAB, memilihkan bahan bangunan sesuai dengan spesifikasi yang ada di juknis DAK, melakukan pengawasan dalam pembangunan, dan membantu dalam pembuatan laporan pertanggung jawaban. Pengelola DAK Fisik di Disdik Kabupaten Agam yang membayar honor fasilitator tersebut yang diambil $5 \%$ dari dana manajemen.

Disdik Kabupaten Agam melakukan satu kali revisi URK, karena usulan data sekolah penerima DAK Fisik Bidang Pendidikan tidak disetujui semuanya, sehingga Disdik harus merubah data SD penerima DAK Fisik disesuaikan dengan bantuan DAK yang diterima dari pusat. Revisi URK tersebut harus disetujui oleh Bupati setempat.

b. Pelaksanaan

Tugas Disdik Kabupaten selanjutnya yaitu menandatangani surat perjanjian pemberian bantuan kegiatan peningkatan prasarana pendidikan DAK Bidang SD dan SMP tahun anggaran berkenaan dengan kepala sekolah penerima DAK. Selain itu, Disdik harus menyelenggarakan bimbingan teknis (Bimtek) pelaksanaan peningkatan prasarana pendidikan kepada kepala sekolah dan komite sekolah, agar memahami secara teknis mekanisme dan tata kelola pelaksanaan kegiatan peningkatan prasarana pendidikan.

Pelaksanaan DAK Fisik terdiri dari dua macam, yaitu peningkatan prasarana pendidikan yang dilakukan secara swakelola dan pengadaan peningkatan sarana pendidikan yang dilakukan melalui pembelian di e-katalog atau dengan e-tender/lelang. Sebelum pelaksanaan pembangunan DAK Fisik dilakukan, Disdik Kabupaten Agam 
melakukan Bimtek kepada kepala sekolah dan komite sekolah. Bimtek berupa sosialisasi agar kepala sekolah dan komite sekolah memahami secara teknis mekanisme dan tata kelola pelaksanaan kegiatan peningkatan prasarana pendidikan berupa rehabilitasi ruang belajar dan pembangunan RKB atau laboratorium IPA.

SD dan SMP penerima bantuan DAK Fisik, sebelum melaksanakan pembangunan DAK Fisik dimulai, pihak sekolah harus membentuk Panitia Pembangunan Sekolah (P2S) yang terdiri dari guru dan komite sekolah. Sebagai Ketua, Sekretaris, dan Bendahara dipilih dari guru di sekolah bersangkutan, sedangkan yang menjadi anggotanya adalah komite sekolah yang ditunjuk ikut serta dalam P2S. Pembiayaan pelaksanaan pembentukan P2S dan persiapan lainnya sebelum DAK Fisik dimulai berasal dari SD atau SMP penerima bantuan DAK Fisik, bukan dari bantuan DAK Fisik.

Setelah sekolah penerima bantuan DAK Fisik Bidang Pendidikan berupa peningkatan prasarana pendidikan, maka Disdik melakukan penanda- tanganan MoU surat perjanjian pemberian bantuan DAK Fisik dengan Kepala SD dan SMP yang mendapatkan bantuan DAK Fisik di Kabupaten Agam. P2S dapat melaksanakan pembangunan DAK Fisik ketika pencairan DAK Fisik tahap 1 cair.

Pencairan DAK Fisik Bidang Pendidikan di Kabupaten Agam dilaksanakan dalam tiga tahap sesuai dengan Peraturan Menteri Keuangan PMK Nomor 112/PMK.7/2017 yang merupakan perubahan dari Peraturan Menteri Keuangan PMK Nomor 50/PMK.7/2017. Pada tahun 2017 terjadi dua kali perubahan Peraturan menteri Keuangan yang berdampak pada perubahan Peraturan Meteri Pendidikan dan Kebudayaan tentang Petunjuk Teknis DAK Fisik Bidang Pendidikan.

Kabupaten Agam untuk menu peningkatan prasarana pendidikan Bidang SD mendapatkan alokasi 67 ruang belajar yang akan direhab dan 2 pembangunan RKB. Sedangkan untuk menu pengadaan koleksi perpustakaan Kabupaten Agam Bidang SD mendapatkan alokasi sebanyak 57 
paket buku. Koleksi perpustakaan yang ada dalam juknis DAK terdiri dari 840 judul buku pengayaan, 10 judul buku referensi, dan 10 judul buku pedoman pendidikan. Jumlah buku dan judul mana saja yang akan dipilih untuk dilelangkan ditentukan oleh Disdik Kabupaten Agam Bidang SD.

Sedangkan Bidang SMP, mendapatkan menu peningkatan prasarana pendidikan, yaitu 77 rehabilitasi ruang belajar dan 5 pembangunan Laboratorium IPA. Sedangkan untuk menu peningkatan sarana pendidikan Bidang SMP mendapatkan 81 peralatan dan media pendidikan.

Untuk pelaksanaan rehabilitasi ruang belajar/kelas dan pembangunan RKB di Bidang SD dapat terlaksana 100\%. Sedangkan untuk pengadaan sarana pendidikan yang melakukan bukan Disdik Kabupaten Agam, tetapi ada Pokja tersendiri yang mengurusi masalah lelang dan pengadaan. Disdik memberikan judul, jumlah, jenis, dan spesifikasi buku yang akan dilelangkan. Koleksi perpustakaan terdiri dari buku pengayaan, buku referensi, dan buku pedoman pendidik yang dipilih oleh Disdik untuk dilelangkan.

Disdik Kabupaten Agam Bidang SD harus mengembalikan bantuan DAK Fisik Bidang Pendidikan untuk peningkatan sarana pendidikan sebesar Rp2,6 Miliar, karena pengadaan koleksi perpustakaan dari DAK Fisik tidak dapat dilaksanakan, sehingga menjadi beban daerah yang masuk dalam APBD Perubahan.

Sedangkan pelaksanaan pembangunan laboratorium IPA dan rehabilitasi ruang belajar di Bidang SMP semuanya terlaksana dengan baik dan mencapai $100 \%$. Begitu pula untuk pengadaan sarana pendidikan berupa peralatan dan media pembelajaran dapat dilaksanakan $100 \%$. Pengadaan sarana pendidikan dapat terlaksana $100 \%$, karena semua barang yang dibutuhkan ada di e-katalog, sehingga Pokja yang mengurusi lelang dan pengadaan dapat langsung memesan melalui e-katalog. Pengadaan melalui e-katalog membutuhkan waktu yang tidak lama, yaitu satu minggu dan pengadaan melalui e-katalog lebih aman dan mudah dibandingkan melalui cara lainnya. 
c. Pengawasan

Pengelola DAK Fisik di Disdik Kabupaten Agam melakukan pengawasan kepada SD dan SMP penerima bantuan peningkatan prasarana pendidikan berupa rehab ruang belajar/kelas dan pembangunan RKB atau laboratorium minimal satu kali. Pengawasan dilakukan untuk mengetahui progress pembangunan dan rehab serta pemanfaatan bantuan DAK Fisik. Selain pengawasan yang dilakukan secara langsung, pengawasan juga dilakukan melalui permintaan kepada kepala sekolah untuk mengirimkan foto dari berbagai sisi melalui WhastApp (WA) setiap minggunya.

Sedangkan pengawasan mengenai pengadaan sarana pendidikan dilakukan melalui panitia penerima hasil pekerjaan (PPHP). Sebelum, peralatan dan/atau media pembelajaran diterima pihak sekolah PPHP yang melakukan pengecekan terlebih dahulu mengenai judul, jumlah, jenis, dan spesifikasi peralatan dan/atau media pendidikan yang akan diterima SMP penerima bantuan DAK Fisik peningkatan sarana pendidikan. Jika ditemui ketidak sesuaian dengan pemesanan maka PPHP akan menginformasikan kembali ke penyedia.

Sedangkan untuk pengadaan sarana pendidikan bidang SD tidak dilakukan pengawasan karena tidak terlaksananya pengadaan koleksi perpustakaan.

\section{d. Pelaporan}

Pelaporan dilakukan secara berjenjang, mulai dari laporan P2S, Kepala Sekolah, Provinsi/kabupaten/Kota, dan Pusat. P2S SD dan SMP penerima bantuan peningkatan prasarana pendidikan membuat laporan pertanggungjawaban kepada kepala sekolah dan Pengelola DAK Fisik di Disdik Kabupaten Agam Bidang SD dan SMP setiap minggu, bulan, dan akhir pelaksanaan sesuai dengan juknis DAK. P2S SD dan SMP membuat laporan pertanggungjawaban disertai dengan bukti fisik, administrasi, dan keuangan.

Laporan mingguan yang dibuat oleh P2S SD dan SMP, meliputi: 1). informasi volume, satuan, dan bobot pekerjaan; 2). prestasi pekerjaan 
mingguan; 3). jumlah dana yang digunakan; dan 4). foto-foto kemajuan pelaksanaan kegiatan mencakup tampak depan, tampak belakang, tampak samping dan tampak dalam yang diambil dari titik tetap/titik yang sama. Sedangkan laporan bulanan meliputi: 1). informasi volume, satuan, dan bobot pekerjaan; 2). prestasi pekerjaan bulanan; 3). jumlah dana yang digunakan; dan 4). foto-foto kemajuan pelaksanaan kegiatan mencakup tampak depan, tampak belakang, tampak samping dan tampak dalam yang diambil dari titik tetap/titik yang sama; c. Dan laporan akhir mencakup: 1). dokumen penyelesaian fisik; 2). dokumen penggunaan dana; dan 3). foto-foto pelaksanaan kegiatan $(0 \%, 40 \%, 70 \%$, dan $100 \%)$ yang diambil dari titik tetap/titik yang sama.

Kepala sekolah harus menyampaikan laporan bulanan dan laporan akhir berdasarkan laporan dari P2S kepada Gubernur dan Bupati. Laporan yang dibuat kepala sekolah, meliputi: a. Laporan bulan yang berisi kemajuan pekerjaan meliputi laporan fisik dan laporan keuangan; b. Laporan akhir meliputi laporan fisik dan laporan keuangan yang disertai dengan uraian masalah yang dihadapi dan solusi yang dilakukan bila terjadi masalah, serta melampirkan foto kemajuan pelaksanaan kegiatan mulai dari $0 \%$, $40 \%, 70 \%$, dan $100 \%$.

Pengelola DAK Fisik di Disdik Kabupaten Agam bidang SD dan SMP juga membuat laporan kepada Bappeda dan Kementerian Pendidikan dan Kebudayaan, yaitu untuk SD ke Direktorat Pembinaan SD dan untuk SMP ke Direktorat Pembinaan SMP melalui aplikasi SIMDAK. Laporan tersebut berisi usulan dan realiasasinya, progress pembangunan, dan kendala yang dihadapi. Laporan tersebut berasal dari laporan P2S yang masuk ke Disdik Kabupaten Agam.

2. Kendala Pelaksanaan DAK Fisik Bidang Pendidikan di Disdik Kabupaten Agam.

Untuk pelaksanaan pembangunan dan rehabilitasi di SD dan SMP tidak ditemui kendala. Begitu pula dalam pengadaan peralatan dan media pendidikan di SMP juga tidak ditemui kendala. Sedangkan, kendala dalam pengadaan sarana pendidikan di SD, yaitu tidak adanya penyedia yang memenuhi kriteria yang 
telah ditentukan oleh Pokja bidang lelang dan pengadaan, sehingga pelaksanaan pengadaan koleksi perpustakaan tidak dapat dilaksanakan karena untuk melakukan lelang kembali waktu yang tersedia tidak mencukupi.

Tidak adanya penyedia yang memenuhi persyaratan, karena penyedia tidak msecara keseluruhan, padahal itu sebagai salah satu syarat untuk menjadi penyedia. Sebagai contoh, penyedia tidak mengisi kolom "berapa lama mereka menjadi penyedia". Pada hal itu menjadi salah satu syarat untuk dipilih menjadi penyedia pengadaan koleksi perpustakaan.

Selain itu, Pokja yang mengurusi lelang dan Pengadaan akan melakukan proses lelang kembali tetapi waktu yang tersedia tidak mencukupi, karena ada batas waktu pelaporan URK dan data kontrak, yaitu 31 Agustus 2017. Sedangkan pada tanggal 21 Agustus 2017 proses lelang baru mau tayang, jika dilihat dari urutan jadwal lelang seperti, pengumuman lelang hingga pengumuman pemenang lelang membutuhkan tahapan waktu yang tidak sebentar minimal 28 hari, sedang waktu yang ada hanya tersisa 10 hari. Itulah yang menyebabkan pengadaan koleksi perpustakaan tidak dapat terlaksana dan itu menjadi tanggung jawab daerah pada APBD Perubahan.

\section{E. Simpulan dan Rekomendasi}

\section{Simpulan}

Pelaksanaan rehabilitasi ruang belajar dan pembangunan RKB di SD dapat dilaksanakan semuanya (100\%). Dan Pelaksanaan rehabilitasi ruang kelas dan pembangunan laboratorium IPA, serta pengadakan peralatan dan media pendidikan di SMP dapat dilaksanakan semuanya (100\%). Rehabilitasi dan pembangunan DAK Fisik dapat dilaksanakan dengan baik dan lancer berkat pelaksanaan yang dilakukan secara swakelola.

Sedangkan untuk pengadaan koleksi perpustakaan di SD tidak dapat dilaksanakan karena tidak ada penyedia yang memenuhi kriteria yang ditentukan oleh Pokja lelang dan pengadaan sebagai penyedia pemenang lelang. Pengadaan peralatan dan media pembelajaran di Bidang SMP dapat dilaksanakan semuanya (100\%), karena barangnya ada semua di ekatalog dan itu mempermudah pengelola DAK dalam pengadaan sarana pendidikan, karena lebih cepat dan aman. 


\section{Rekomendasi}

Waktu pelaksanaan lelang hendaknya batas akhirnya hingga bulan Oktober, karena ada lembaga lain yang terkait dalam pelaksanaan lelang.

\section{DAFTAR PUSTAKA}

Adisasmita, Rahardjo, 2011. Pembiayaan Pembangunan Daerah. Yogyakarta: Graha Ilmu, 2011. Hlm.24.

Abdullah, Syukur, 1987. Kumpulan Makalah "Study Implementasi Latar Belakang Konsep Pendekatan dan Relevansinya Dalam Pembangunan". Ujung Pandang: Persadi. Hlm.41.

Badan Pusat Statistik, 2018. Kabupaten Agam Dalam Angka 2018. Lubuk Basung, Badan Pusat Statistik Kabupaten Agam, https://agamkab. bps.go.id/publication/2018/08/16/61f2 34670dec4ca6f38c0024/kabupatenagam-dalam-angka-2018.html, diakses 20 Februari 2018.

Kamus Besar Bahasa Indonesia. Pengertian Pelaksanaan, https://kbbi.web.id/pelaksanaan diakses 25 Februari 2019.

Republik Indonesia, 2005. Peraturan Presiden Republik Indonesia Nomor 19 Tahun 2005, Tentang Standar Nasional Pendidikan. Jakarta: Kementerian Hukum dan Hak Asasi Manusia.

Republik Indonesia, 2016. Peraturan Presiden Republik Indonesia Nomor 123 Tahun 2016, Tentang Petunjuk
Teknis Dana Alokasi Khusus Fisik. Jakarta: Kementerian Hukum dan Hak Asasi Manusia.

Republik Indonesia, 2017. Peraturan Menteri Pendidikan dan Kebudayaan Republik Indonesia Nomor 26 Tahun 2017 Tentang Perubahan Atas Peraturan Menteri Pendidikan dan Kebudayaan Nomor 8 Tahun 2017 Tentang Petunjuk Teknis Bantuan Operasional Sekolah. Jakarta: Kementerian Hukum dan Hak Asasi Manusia.

Satropoetro, Santoso, 1982. Pelaksanaan Latihan, Jakarta: Gramedia, 1982, Hlm. 183. 